\title{
Is reassessment of radiographs taken from pediatric patients useful for detecting unrecognised hip dysplasia?
}

\author{
Reşit Sevimli ${ }^{1}$, Mehmet Fethi Ceylan ${ }^{1}$, Emrah Yıldırım ${ }^{1}$, Mehmet Aslan $^{2}$, Gökay Görmeli $^{3}$ \\ ${ }^{1}$ Department of Orthopedics and Traumatology, Inönü University Turgut Özal Medical Center, Malatya, Turkey \\ ${ }^{2}$ Department of Pediatrics, Inonu University School of Medicine, Malatya, Turkey \\ ${ }^{3}$ Department of Orthopaedics and Traumatology, liv Hospital, Istanbul, Turkey
}

\begin{abstract}
Developmental Dysplasia of the Hip (DDH) is an entity that may be congenital as well as developing during infancy or childhood and include anatomic disorders of the hips. Moreover, DDH is of great importance with the possibility of being diagnosed late and causing disabilities in patients. Despite the fact that there wasn't any not a patient with complaints of hip dislocation in this study, the unrecognized cases that admitted to the clinics due to other complaints were also presented.

Hip and pelvic radiographs taken from 10.000 children who were referred to emergency and pediatric outpatient clinics of our department with other complaints between 2009-2016 were evaluated. Six patients who had high acetabular index according to the measurements calculated from 4.000 radiographs that were appropriate for evaluation and who were thought to have unrecognized were recalled and their hip radiographs were evaluated.

Six patients with suspected hip dysplasia detected from 4000 radiographs, which were suitable for the measurement techniques, were called to the control examination. In the physical examinations and radiographs, abnormal radiographic views of a patient with complete dislocation and two patients with dysplastic hip according to their first radiographs were completely resolved.

When treatment of DDH can be performed with simple instrumentation or limited surgical interventions in the early infancy, complicated surgical interventions are required during age of walking and after this period, which reduce the success rate. Therefore, we think that every child under one year old who has referred to the clinics for other reasons and those with hip or pelvis graphs are required to be examined in terms of DDH.
\end{abstract}

Key Words: Hip dysplasia, pelvis graphy, emergency polyclinic

\section{Introduction}

Developmental dysplasia of the hip (DDH) is a preventable disorder of the hip pathology. Normal development of the hip can be provided by early diagnosis and treatment of DDH. In delayed treatment, complications such as avascular necrosis, redislocation, residual acetabular dysplasia and coxarthrosis have been reported $(1,2)$.

A great deal of late-diagnosed cases of DDH have been detected in countries where early screening programs are not available $(3,4)$. Even in studies conducted in regions where the selective screening program has been implemented, diagnosing hip dislocations late were detected (4). Songur et al. (3) stated that $5.9 \%$ of hip pathologies were detected in the patients' radiographs taken because of problems other than hip problems. However, it was unclear whether the children with $\mathrm{DDH}$, who were detected in this study, included any risk factors. At the same time, it was also unclear whether a treatment was administered or not.

The aim of this study was to detect the pathological hips in radiographs taken for reasons other than non-orthopedic problems from digital radiographic imaging archive of our university hospital. The pathological hip treatments were requested to perform as soon as possible by informing these children's families.

\section{Materials and methods}

The retrospective study was confirmed by ethical committee (Acceptance no: 2016/9-16). 10.000 children who applied between 2009 and 2016 were included in this study. Patient age at the time of radiography ranged from 6 month to 14 years. The pelvis, abdomen and thorax plain graphs recorded 
in the digital radiography archive of our university hospital were examined. We examined the rate of hip dysplasia or dislocations on radiographs images taken for non-orthopedic purposes.

Patients with a radiologically visible femoral head and open triradiate cartilage were included in the study. Exclusion criteria are teratologic cases such as hydrocephalus, myelomeningocele, cerebral palsy. In addition, poor quality and extremely tilted or rotated radiographic images were excluded.

Acceptable radiographs were assessed for pelvic tilt according to the method described by Ball and Kommenda. Additional assessment for rotation according to method described by Tönnis and Brunken were excluded. Also, hips dislocation or subluxation were determined according to the relationship between the femoral head epiphysis with the Perkins-Ombredanne quadrant and the Shenton-Menard line (5).

All the radiographs included in the study were recorded in the digital environment. Acetabular index values of dysplastic acetabular hips were measured in digital environment using PACS software system (Sectra Workstation IDS7 2015, Linköping, SWEDEN). In the study conducted by Akel et al. (6), acetabular index values measured for patients were interpreted according to the cutoff data for acetabular dysplasia.

The families of children with hip disorders were communicated via their contact information in hospital records. The age of these children, their complaints when admitted, risk factors for hip dysplasia, whether or not a hip ultrasonography (US) for screening purposes were performed and information about additional diseases were learned from hospital records or their families. After informing these families about the children's hips problem, the treatment and follow-up of the patients with DDH were performed.

\section{Results}

The initial application complaints for 4000 children included in the study were detected as follow: nausea and vomiting (31.5\%), abdominal pain (21.5\%), cough (20\%), high fever $(9 \%)$, dizziness $(5.5 \%)$, convulsion $(3.5 \%)$ and other complaints $(9 \%)$.

6 out of 4000 patients (1.5\%) in accordance with the determined radiological criteria were diagnosed with DDH. It was detected that only one of them was treated with a hip abduction orthosis because she was diagnosed with DDH in an another hospital after 6 months a radiography was taken in our hospital. It was learned from families whose other children did not have any complaints and problems related to their hips. For six patients diagnosed with dysplasia, the reasons of first admission to the hospital, acetabular index values and the risk factors such as the swaddling habit were shown in table (Table 1).

Spontaneous reduction of the hip was detected on his last radiograph 2 years later taken from the patient number six with subluxated left hip on his first radiograph (Figure 1,2). The patient was treated with abduction orthosis because the disorder of the acetabular dysplasia continued. Polyclinic control was recommended to the other patients six months later.

\section{Discussion}

The most important issue in the treatment of DDH is early diagnosis and treatment. When treatment for pathological hip is administered within the first 3 months, normal joint development is expected (1). However, when the effectiveness of conservative treatment decreases, the development of arthrosis is expected in diagnosis delays more than 3-6 months (7).

Table 1. The data related to patients diagnosed with DDH

\begin{tabular}{llllllll}
\hline Patients & Gender & $\begin{array}{l}\text { Application } \\
\text { complaint }\end{array}$ & $\begin{array}{l}\text { Previous } \\
\text { USG scan }\end{array}$ & First girl & $\begin{array}{l}\text { Swaddle } \\
\text { habit }\end{array}$ & First AI & $\begin{array}{l}\text { Last } \\
\text { AI }\end{array}$ \\
\hline First & F & abdominal pain & Type 1 & - & + & R;30 L;32 & \\
Second & M & dysuria & - & - & + & R;29 L:31 & \\
Third & F & high fever & Type 1 & - & + & R;18 L:27 & \\
Fourth & F & cough & - & + & + & R;26 L;23 \\
Fifth & F & cough & - & - & - & R;32 L:27 \\
Sixth & M & high fever & Type 1 & - & + & R;23 \\
& & & & & & L;42(L) \\
& & & & & DYSLOCATED \\
\hline
\end{tabular}




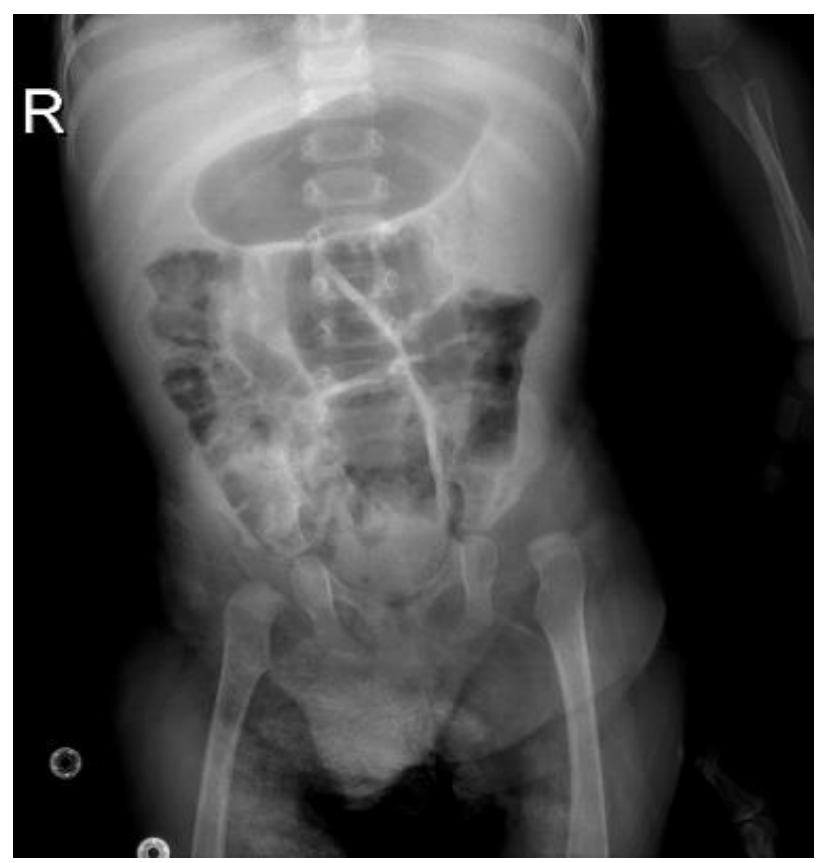

Fig. 1. The radiographic view of the patient's left hip. All abdominal radiographs were taken after the patient with a complaint of high fever was examined in the emergency polyclinic.

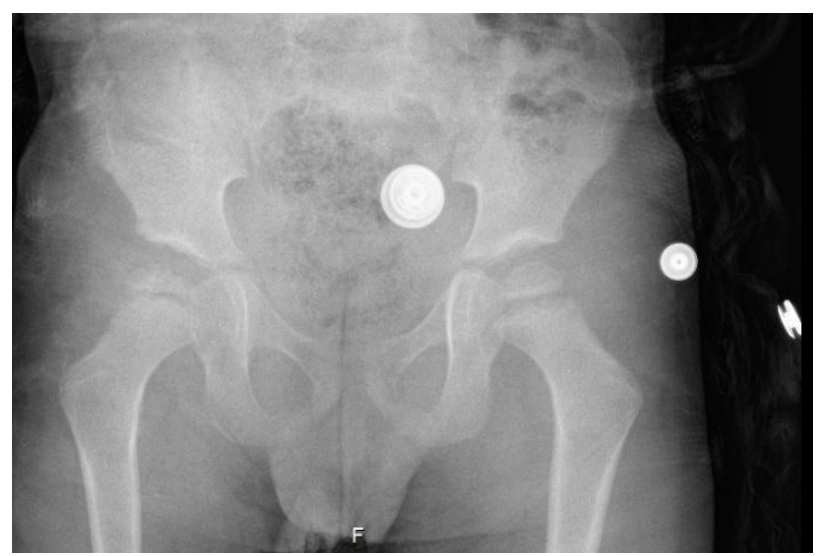

Fig. 2. Radiograph of the reducted hip from same patient after 2 years.

In the multicenter studies, Mulpuri et al. (8) emphasized that DDH with late diagnosis more than 3 months were related to swaddling habit and head presentation delivery. Also, Sharpe and Azzopardi reported low birth weight, female gender, vertex presentation, normal delivery, rural birth, and discharge from hospital less than 4 days after birth as risk factors for late diagnosed DDH $(9,10)$. In our study, there was history of swaddling use in five of the six patients diagnosed with DDH.

In many studies of the literature, patients with late diagnosed DDH had rate of up to $33 \%$ in the cases treated appropriately in addition to detected by early clinical and USG screening. In these studies, it was emphasized that, even if a normal hip was obtained ultrasonographically as a result of early treatment of patients with $\mathrm{DDH}$, the follow-up of the hips should also be performed radiographically (11-13).

In the meta-analysis conducted by Shorter et al., (14) they emphasized that although both the universal and selective early screening studies were performed by USG, the rates of late-diagnosed DDH could not be reduced. Also, in other studies, it was found that symptomatic hip dysplasia developed at different rates during adolescent period in cases of DDH detected by selective early screening and treated successfully. In these studies, it was emphasized that, these hips being treated should be followed until they got mature $(15,16)$. In our study, six patients diagnosed with DDH should be followed up radiographically until their hips got mature.

Radiographic assessment of the hips of children older than 6 months with a risk factor, particularly in countries where any early screening programs for DDH has not been performed, is useful for detecting unrecognized patients with DDH (3). The detection of unrecognized six patients with $\mathrm{DDH}$ in our study suggested the necessity of examining hip radiographs weekly or monthly taken before for another reason from the X-ray archive.

It was possible to detect a case report in which the patient diagnosed with DDH when he was 1.5 years old, although he was admitted to the hospital due to different causes rather than extremity problems (17). The risk factors of this patient such as being the first daughter and positive examination findings are thoughtprovoking. Pediatricians and family physicians should be more sensitive to avoid such cases when assessing hip radiographs for DDH, especially for children with risk factors. Increasing knowledge and consciousness of medical students for DDH will also contribute to the early recognition of this disease (18). The fact that the available pathological view of hip radiographs from 6 patients were unrecognized in our study suggested the lack of knowledge and/or care of the relevant physicians about pelvis $\mathrm{x}$ ray evaluation.

It should be kept in mind that pediatricians who have frequent contacts with young children for such reasons as routine immunization in the early stages, diarrhea, cold and influenza are at risk in terms of medicolegal issues due to late diagnosis of DDH (17). Rombouts et al. (19) stated that in the US the most frequent court case on the musculoskeletal area for pediatricians is the late 
diagnosis of DDH. In order to reduce aforementioned risk, when a radiograph is taken for children older than 6 months, even if the hips are controlled by USG within the first 3 months and normal USG results are determined, it is useful to include the hip joints within sight. It is important that radiology technicians are trained in this area.

The limitations of our study were its retrospective design, evaluation of a limited number of patients and absence comparison group. There is a requirement for a larger patient population and prospective, multicentered and randomized trials in order to better understand the issues such as the necessity of not just following up periodically the hip radiographs of children older than 6 months with a risk factor for $\mathrm{DDH}$, but also frequency and duration of radiological follow-up.

In conclusion, when a plain radiograph is taken for any reason especially from children older than 6 month old with risk factors for DDH, the examination of radiography included hip joints is important for the diagnosis of unrecognized children with DDH. Especially in areas where early screening for DDH has not been performed, the analysis of hip radiographs from archives by specialists periodically is useful for detecting unrecognized patients with DDH.

Conflict of interest: The authors declare no conflict of interest.

\section{References}

1. Angliss R, Fujii G, Pickvance E, Wainwright AM, Benson MK. Surgical treatment of late developmental displacement of the hip results after 33 years. J Bone Joint Surg Br 2005; 87: 384-394.

2. Ning B, Yuan Y, Yao J, Zhang S, Sun J. Analyses of outcomes of one-stage operation for treatment of late-diagnosed developmental dislocation of the hip: 864 hips followed for 3.2 to 8.9 years. BMC Musculoskelet Disord 2014; 15: 401.

3. Songur M, Akel I, Karahan S, Kuzgun U, Tümer Y. Prevalence of untreated hip dislocation in Turkish children aged 6 months to 14 years. Acta Orthop Traumatol Turc 2011; 45: 215-220.

4. Mamouri GH, Khatami F, Hamedi AB. Congenital dislocation of the hip in newborns of Mashhad City. The Internet Journal of Pediatrics and Neonatology 2004; 4: 1-5.

5. Laborie LB, Markestad TJ, Davidsen $\mathrm{H}$, et al. Selective ultrasound screening for developmental hip dysplasia: effect on management and late detected cases. A prospective survey during 19912006. Pediatr Radiol 2014; 44: 410-424.
6. Akel I, Songür M, Karahan S, Yilmaz G, Demirkıran HG, Tümer Y. Acetabular index values in healthy Turkish children between 6 months and 8 years of age: a cross-sectional radiological study. Acta Orthop Traumatol Turc 2013; 47: 38-42.

7. Tönnis D. General radiography of the hip joint. In: Tönnis D, editor. Congenital dysplasia and dislocation of the hip. English ed. Heidelberg: Springer-Verlag 1987: 108-113.

8. Mulpuri K, Emily KS, Janice A, et al. What Risk Factors and Characteristics Are Associated With Late Presenting Dislocations of the Hip in Infants? Clin Orthop Relat Res 2016; 474: 1131-1137.

9. Sharpe P, Mulpuri K, Chan A, Cundy PJ. Differences in risk factors between early and late diagnosed developmental dysplasia of the hip. Arch Dis Child Fetal Neonatal Ed 2006; 91: 158-162.

10. Azzopardi T, Van Essen P, Cundy PJ, Tucker G, Chan A. Late diagnosis of developmental dysplasia of the hip: an analysis of risk factors. J Pediatr Orthop B 2011; 20: 1-7.

11. Sarkissian EJ, Sankar WN, Zhu X, Wu CH, Flynn JM. Radiographic follow-up of DDH in infants: are X-rays necessary after a normalized ultrasound? J Pediatr Orthop 2015; 35:551-555.

12. Alexiev VA, Harcke HT, Kumar SJ. Residual dysplasia after successful Pavlik harness treatment: early ultrasound predictors. J Pediatr Orthop 2006; 26: 16-23.

13. Dornacher D, Cakir B, Reichel H, Nelitz M. Early radiological outcome of ultrasound monitoring in infants with developmental dysplasia of the hips. J Pediatr Orthop B 2010; 19: 27-31.

14. Shorter D, Hong T, Osborn DA. Cochrane Review: Screening programs for developmental dysplasia of the hip in newborn infants. Evid Based Child Health 2013; 8: 11-54.

15. Modaressi K, Erschbamer M, Exner GU. Dysplasia of the hip in adolescent patients successfully treated for developmental dysplasia of the hip. J Child Ortho 2011; 5: 261-266.

16. Sink EL, Ricciardi BF, Torre KD, Price CT. Selective ultrasound screening is inadequate to identify patients who present with symptomatic adult acetabular dysplasia. J Child Orthop 2014; 8: 451-455.

17. Kutlu R, Çivi S. The importance of diagnosing developmental dysplasia of the hip in family medicine: a case report. Türk Aile Hek Derg 2007; 11: 140-142.

18. Ceylan MF, Görmeli G, Korkmaz MF, Karataş M, Ekinci Ş, Yoloğlu S. Knowledge and awareness of developmental dysplasia of the hip in medical students in eastern Turkey. Pensee 2014; 76: 168172.

19. Rombouts JJ, Rombouts-Godin V. Delayed detection of hip dislocation: is the physician to blame? Pediatrie 1993; 48: 327-334. 